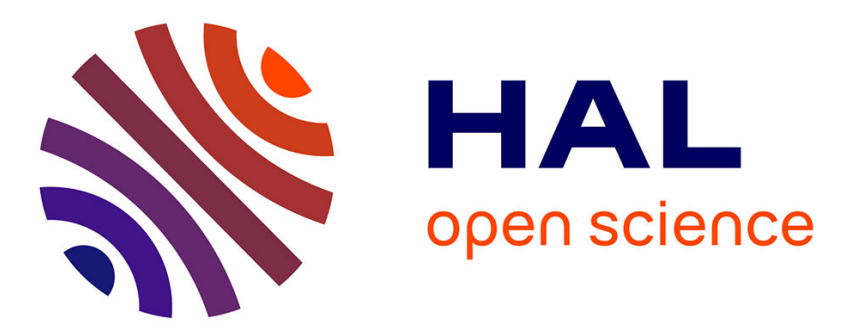

\title{
Quasicrystal plasticity in the framework of a constitutive model: Interaction of the microstructural parameters at high strain-rates
}

Marc Heggen, M. Feuerbacher

\section{- To cite this version:}

Marc Heggen, M. Feuerbacher. Quasicrystal plasticity in the framework of a constitutive model: Interaction of the microstructural parameters at high strain-rates. Philosophical Magazine, 2008, 88 (13-15), pp.2325-2331. 10.1080/14786430701854820 . hal-00513855

\section{HAL Id: hal-00513855 \\ https://hal.science/hal-00513855}

Submitted on 1 Sep 2010

HAL is a multi-disciplinary open access archive for the deposit and dissemination of scientific research documents, whether they are published or not. The documents may come from teaching and research institutions in France or abroad, or from public or private research centers.
L'archive ouverte pluridisciplinaire $\mathbf{H A L}$, est destinée au dépôt et à la diffusion de documents scientifiques de niveau recherche, publiés ou non, émanant des établissements d'enseignement et de recherche français ou étrangers, des laboratoires publics ou privés. 


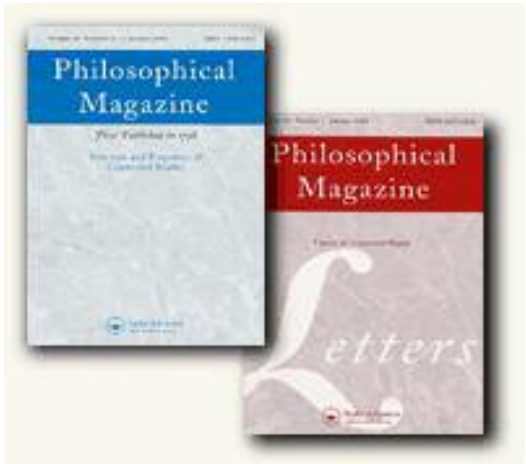

Quasicrystal plasticity in the framework of a constitutive model: Interaction of the microstructural parameters at high strain-rates

\begin{tabular}{|r|l|}
\hline Journal: & Philosophical Magazine \& Philosophical Magazine Letters \\
\hline Manuscript ID: & TPHM-07-Oct-0275.R1 \\
\hline Journal Selection: & Philosophical Magazine \\
\hline $\begin{array}{r}\text { Date Submitted by the } \\
\text { Author: }\end{array}$ & $28-$ Nov-2007 \\
\hline Keywords: & $\begin{array}{l}\text { Constitutive equations, dislocations, plasticity, quasicrystalline } \\
\text { alloys, quasicrystals } \\
\text { Fenerthoerperforschung } \\
\text { Festhörperforschung }\end{array}$ \\
\hline Keywords (user supplied): & constitutive equations, dislocations, plasticity \\
\hline &
\end{tabular}

\section{\) ScholarONE" \\ Manuscript Central}




\title{
Quasicrystal plasticity in the framework of a constitutive model:
}

\section{Interaction of the microstructural parameters at high strain-rates}

\author{
Marc Heggen, Michael Feuerbacher \\ Institut für Festkörperforschung, Forschungszentrum Jülich GmbH, \\ D-52425 Jülich, Germany
}

\begin{abstract}
A unified description of quasicrystal plasticity in terms of a quantitative model using constitutive equations was presented by Feuerbacher and coworkers in 2001 [1]. In a later work, the model was successfully applied to a wide range of experimental parameters where various stress-strain behaviour was observed [2]. At high strain-rates, for example, the occurrence of a low-strain work-hardening stage, the formation of a stress maximum at around $5 \%$, and work softening at higher strains was observed. In the present work, the complex stress-strain behaviour of quasicrystals at high strain rates is analysed in terms of the constitutive model. The evolution of the two microstructural parameters, the dislocation density and the order parameter, their interaction with other microstructural parameters and the influence on the macroscopic plastic deformation behaviour are analysed and discussed.
\end{abstract}

Keywords: Al-Pd-Mn quasicrystal; plastic deformation; work softening; work hardening, constitutive model; plasticity. 


\section{INTRODUCTION}

The plasticity of quasicrystals shows very particular features such as the lack of work hardening at high strains $[3,4,5,6,7]$. This behaviour was shown to be accompanied by a decrease of the dislocation density $[5,8,9]$. A quantitative model of quasicrystal plasticity based on a system of constitutive equations involving the stress-strain behaviour and the dislocation density evolution was presented by Feuerbacher and co-workers in 2001 [1]. This model reproduces the characteristic features of work softening and the decrease in dislocation density. In a later work, the model was successfully applied to a wide range of experimental parameters in which various stress-strain behaviour was observed [2]. Here, work softening after the lower yield point is observed at medium strain rates of $10^{-5} \mathrm{~s}^{-1}\left(730\right.$ and $\left.760{ }^{\circ} \mathrm{C}\right)$ and $10^{-4}\left(760{ }^{\circ} \mathrm{C}\right)$. At strain rates of $10^{-3} \mathrm{~s}^{-1}\left(730\right.$ and $\left.760{ }^{\circ} \mathrm{C}\right)$ and $10^{-4} \mathrm{~s}^{-1}\left(730{ }^{\circ} \mathrm{C}\right)$, respectively, a work-hardening regime is observed after the lower yield point, giving rise to a second stress maximum at about $5 \%$ strain. This second maximum is followed by work softening at higher strains. In contrast, at the lowest strain rates of $10^{-6} \mathrm{~s}^{-1}$ and $0.7 \times 10^{-6} \mathrm{~s}^{-1}$ the stress remains at an almost constant level after the lower yield point and neither work softening nor hardening is found. The stress-strain curves computed according to the constitutive model reproduce all essential features of the experimental curves remarkably well. However, the interplay of the microstructural parameters of the constitutive model yielding such complex deformation behaviour, in particularly combining stages of work hardening and softening, is weakly understood.

In the present paper, we briefly recall the constitutive model of quasicrystal plasticity and discuss the results of a deformation experiment at $10^{-3} \mathrm{~s}^{-1}$ showing work hardening as well as work softening. The evolution of the microstructural parameters dislocation density and order parameter, their interaction with other microstructural factors like the dislocation velocity, and 
finally their influence on the macroscopic plastic deformation behaviour are discussed in terms of the constitutive model. We show that the constitutive model allows for a comprehensive treatment of the characteristic phenomena of the plasticity of icosahedral Al-Pd-Mn.

\section{CONSTITUTIVE MODEL}

The constitutive model of Feuerbacher et al. [1] employs two microstructural parameters, the dislocation density $\rho$ and the order parameter $\lambda$. These are the basic parameters determining the stress-strain behaviour. It is assumed that the degree of order is decreased by dislocations moving through the quasicrystalline structure. The decrease of order is proportional to the increase of plastic strain $\varepsilon_{\text {plast }}$ and the current state of order $\lambda$. On the other hand diffusional reordering processes restore the order of the quasicrystal. We assume that the increase of order with time is proportional to $(1-\lambda)$, which is a measure of the order destroyed. Therefore, the evolution of the order parameter $\lambda$ is described by the Ansatz

$$
d \lambda\left(\varepsilon_{\text {plast }}\right)=-\lambda \frac{d \varepsilon_{\text {plast }}}{\varepsilon_{0}}+(1-\lambda) \frac{d t}{\tau_{0}},
$$

where $\tau_{0}$ is a characteristic time constant for the reordering process.

The macroscopic plastic strain rate $\dot{\varepsilon}_{\text {plast }}$ is given by the Orowan equation [10]

$$
\dot{\varepsilon}_{\text {plast }}=m_{s} \rho b v
$$

where $m_{s}$ is the average Schmidt factor, $\rho$ is the dislocation density and $b$ the average magnitude of the dislocation Burgers vector [11]. The dependence of the dislocation velocity on the applied stress is described by the power law 


$$
v=B\left(\frac{\sigma}{\hat{\sigma}}\right)^{m},
$$

where $B$ and $m$ are temperature-dependent parameters and $\hat{\sigma}$ is an internal variable that can be regarded as a "reference stress" [12], which reflects the current microstructural state of the material. The reference stress contributions are given by

$$
\hat{\sigma}=\sigma_{0}+\alpha \mu b \sqrt{\rho(\varepsilon)}+\Delta \sigma \lambda(\varepsilon)
$$

The first term, $\sigma_{0}$, is a constant background friction stress. The second term describes the stress contribution due to dislocation-dislocation interactions (Taylor part) and is proportional to the square root of the strain-dependent dislocation density. The parameter $\alpha$ is of the order of unity and $\mu$ is the shear modulus [13]. The third term represents a quasicrystal-specific friction stress. This stress contribution is proportional to the strain-dependent order parameter $\lambda$. The parameter $\Delta \sigma$ describes the flow-stress contribution originating from the destruction of order by the movement of dislocations in the quasicrystalline material.

The total strain $\varepsilon$ is the sum of the plastic strain $\varepsilon_{\text {plast }}$ and the elastic strain $\varepsilon_{\text {elast }}=\sigma / E$, where $E$ denotes Young's modulus. Combining these equations with Eqs (2) and (3) we obtain

$$
\frac{d \sigma}{d \varepsilon}=E\left(1-\frac{m_{s} \rho b B(\sigma / \hat{\sigma})^{m}}{\dot{\varepsilon}}\right) .
$$

To determine the evolution of the dislocation density, $\rho$, we consider dislocation multiplication and dynamic recovery, which both depend on plastic strain, and we account for static recovery, which depends on time only. The change of $\rho$ with plastic strain is described by

$$
\frac{d \rho}{d \varepsilon_{\text {plast }}}=\frac{M}{b} \sqrt{\rho}-\frac{Y}{b} \rho
$$


[12]. The first term corresponds to the athermal storage of dislocations and involves a multiplication parameter $M$. The second term, entering with a negative sign, describes the annihilation of moving dislocations (dynamic recovery). $Y$ is a characteristic annihilation distance that depends on the order parameter according to

$$
Y=\frac{Y_{0}}{1+\left(\Delta \sigma / \sigma_{0}\right) \lambda},
$$

where $Y_{0}=\mu b / \sigma_{0}$ is a constant.

\section{RESULTS AND DISCUSSION}

In order to elucidate the interplay between the microstructural parameters, we will follow their evolution in detail and investigate the correlation with the stress-strain behaviour using a curve at $10^{-3} \mathrm{~s}^{-1}$ and $730^{\circ} \mathrm{C}$. Figure 1 shows an experimental (solid line) and a computed stressstrain curve (broken line). The latter curve was computed by numerical integration of the set of equations (1), (5) and (6) using the parameters in Table 1. The free parameters were determined by fitting a complete set of stress-strain curves at four different strain rates and the corresponding experimental dislocation densities (cf. [2]). Figure 2 a shows the stress contributions according to Equation (4), the constant background friction stress, the Taylor part, and the quasicrystalspecific stress part, to the total stress. The upper curve represents the total stress according to the broken line of Figure 1. The proportions of different stress contributions change according to the evolution of the microstructural parameters $\rho$ and $\lambda$. The individual contributions can be calculated by multiplying the corresponding terms of Equation (4) with the stress dependent factor $\frac{\sigma(\varepsilon)}{\hat{\sigma}(\varepsilon)}$, which relates the fraction of the respective contribution of the reference stress $\hat{\sigma}$ to 
the total stress $\sigma$. The lower curve in Figure 2 a is the Taylor contribution to the total stress, the middle curve represents the Taylor contribution plus the quasicrystal contribution $\Delta \sigma \lambda(\varepsilon)$ to the total stress. Hence, the difference between the lower curve and the middle curve corresponds to the quasicrystal contribution. Furthermore, the difference between the middle curve and the upper curve corresponds to the contribution of the background stress $\sigma_{0}$ to the total stress.

To make connection to the microstructural parameters, we show the plastic strain rate $\dot{\varepsilon}_{\text {plast }}$ (figure $2 \mathrm{~b}$ ), the dislocation velocity $v$ according to Equation (3) (figure $2 \mathrm{c}$ ), the dislocation density and the rate of dislocation production and annihilation (figures $2 \mathrm{~d}$ and e), and the order parameter $\lambda$ (figure $2 \mathrm{f}$ ) as a function of the total strain $\varepsilon$. The evolution of the Taylor contribution to the total stress in Figure 2 a reflects the evolution of the dislocation-density shown in Figure $2 \mathrm{~d}$. At the beginning of the deformation experiment the stress increases elastically. The dislocation density is low and hence the Taylor contribution to the stress is small. Before reaching the upper yield point, the dislocation velocity increases strongly with increasing stress (cf. Equation 3) - plastic straining of the sample is setting in. With the increase of the plastic strain rate, dislocation storage according to Equation (6) commences. The storage of dislocations is reflected in the strong increase of the dislocation density (Figures $2 \mathrm{~d}$ and e) and the increase of the Taylor contribution.

The strong increase of the dislocation density after the upper yield point leads to a strong decrease of the dislocation velocity (Figure 2 c) according to the Orowan equation (2). Hence the total stress $\sigma$ decreases according to Equation (3). As a consequence, the elastic strain contribution decreases as well leading to a plastic strain rate that is higher than the applied strain rate (Figure $2 \mathrm{~b}$ ). After the upper yield point at $1.28 \%$, the maximum plastic strain rate of $1.62 \times$ 
$10^{-3} \mathrm{~s}^{-1}$ is reached at $1.45 \%$. The rate of dislocation production and annihilation shows two maxima. The first one at $1.68 \%$ corresponds to the maximum plastic strain rate, and the second one at $2.64 \%$ corresponds to the maximum dislocation density. The relation between dislocation production and strain rate on the one hand and dislocation density on the other hand are both expressed by which enters Equation (6). The strong increase of the dislocation density (cf. Figure 2 d) leads to an increase of dislocation-dislocation interactions and a strong increase of the Taylor contribution according to Equation (4) so that the total stress increases at strains between 2.3 and $6.0 \%$. With the increase of the dislocation density the annihilation by dynamic recovery increases as well. As Equation (6) shows, dynamic recovery outruns dislocation multiplication at high dislocation densities.

With the onset of plastic deformation, disordering of the structure is initiated according to Equation (1), which is directly reflected in the sharp drop of the order parameter at $1.4 \%$ in Figure $2 \mathrm{f}$. The decrease of order leads to a decrease of the quasicrystal part to the reference stress according to Equation (4). Furthermore, the decrease of order influences the dislocation velocity and the stress-strain curve via Equations (3) and (2). Additionally, the decrease of order leads to a higher annihilation rate of dislocations, since the annihilation distance increases with decreasing order parameter $\lambda$ (Equation 7). As a result, the dislocation density as well as the Taylor contribution of the stress decrease at high strains according to Equations (6) and (4). Moreover, Fig. 2 a shows that the maximum of the Taylor contribution (white arrowhead) is located at higher strains than the second maximum of the stress-strain curve (black arrowhead). This shift of the stress maximum to lower strains is caused by the decreasing quasicrystal contribution. 
In conclusion, a complex deformation behaviour with stages of work hardening and softening is observed at high strain rates. This complex behaviour is comprehensively described in the framework of the constitutive model. The interplay of the microstructural parameters dislocation density and order parameter and the stress-strain curve was demonstrated. Taylor hardening, due to the strong increase of the dislocation density is the reason for an increase of the stress after the lower-yield stress. However, disordering of the structure during plastic deformation counteracts hardening in two different ways. On one hand it directly influences the stress-strain curve via the quasicrystal stress part, which is only a small fraction of the total stress. On the other hand disordering leads to a higher annihilation rate of dislocations and leads to a decrease of the dislocation density. As a result, the Taylor contribution of the stress decreases and work softening sets in.

\section{REFERENCES}

[1] Feuerbacher M., Schall, P., Estrin, Y., and Brechet, Y., (2001), Phil. Mag. Lett., 81, 473.

[2] Heggen, M., Feuerbacher, M., (2004), MRS Proc. 805, LL5.1.1.

[3] Kang, S.S., and Dubois, J.M., (1992), Phil. Mag. A, 66, 151.

[4] Wollgarten, M., Beyss, M., Urban, K., Liebertz, H., and Köster, U., (1993), Phys. Rev. Lett., $71,549$.

[5] Feuerbacher M., Metzmacher, C., Wollgarten, M., Urban, K., Baufeld, B., Bartsch, M., and Messerschmidt, U., (1997), Mat. Sci. \& Eng. A, 226-228, 943.

[6] Heggen, M., Feuerbacher, M., Schall, P., Klein, H., Fisher, I.R., Canfield, P.C., and Urban, K., (2000), Phil. Mag. Lett., 80, 129.

[7] Imai Y., Shibuya, T., Tamura, R., and Takeuchi, S., (2004), J. Non-Cryst. Sol. 334\&335, 444.

[8] Schall, P., Feuerbacher, M., Bartsch, M., Messerschmidt, U., and Urban, K., (1999), Phil. Mag. Lett., 79, 785. 
[9] Heggen, M., Feuerbacher, M., Lange, T., and Urban, K., (2002), J. Alloys \& Comp. 342, 333.

[10] Evans, A.G., and Rawlings, R.D., (1969), Phys. Stat. Sol., 34, 9.

[11] Feuerbacher M., (1996), Ph.D.-thesis, RWTH-Aachen, „Mechanische Eigenschaften von ikosaedrischen Al-Pd-Mn Quasikristallen“, Jül-3300, ISSN 0944-2952.

[12] Kocks, U.F., (1976), J. Eng. Mater. Technol., 98, 76.

[13] Estrin Y., (1996), Unified Constitutive Laws of Plastic Deformation, (Eds. A. Krausz and K. Krausz), Academic press, p.69.

[15] Messerschmidt, U., Bartsch, M., Geyer, B., Feuerbacher, M., and Urban, K., (2000), Phil. 


\section{FIGURE CAPTIONS}

Figure 1: Experimental (solid line) and computed (broken line) stress-strain curves at $10^{-3} \mathrm{~s}^{-1}$ and $730^{\circ} \mathrm{C}$. Both curves show the appearance of a second stress maximum at around $5 \%$ strain.

Figure 2: (a) Computed stress contributions, i.e. the Taylor part (light grey), the quasicrystal part (white) and the background stress (dark grey), at $730{ }^{\circ} \mathrm{C}$ and $\dot{\varepsilon}=10^{-3} \mathrm{~s}^{-1}$. The arrowheads indicate local maxima of the stress contributions. (b) Plastic strain rate, (c) dislocation velocity, (d) dislocation density, (e) rate of dislocation production and annihilation, and (f) order parameter. 
TABLE / TABLE CAPTION

\begin{tabular}{cccc}
\hline & $\mathbf{7 3 0}{ }^{\circ} \mathbf{C}$ & & \\
Parameter & Value & free/fixed & Ref. \\
\hline$\Delta \sigma$ & $130 \mathrm{MPa}$ & free & \\
$\sigma_{0}$ & $65 \mathrm{MPa}$ & free & \\
$\varepsilon_{0}$ & 0.1 & free & \\
$\tau_{0}$ & $2 \times 10^{4} \mathrm{~s}$ & free & \\
$B$ & $4.5 \times 10^{-9} \mathrm{~m} \mathrm{~s}^{-1}$ & free & \\
$M$ & 0.38 & free & \\
$Y_{0}$ & $7.8 \times 10^{-9}$ & free & \\
$\mu$ & $80 \mathrm{GPa}$ & fixed & {$[11]$} \\
$B$ & $1.83 \times 10^{-10} \mathrm{~m}$ & fixed & {$[11]$} \\
$\rho$ & $2 \times 10^{11} \mathrm{~m}^{-2}$ & fixed & {$[11]$} \\
$E$ & $80 \mathrm{GPa}$ & fixed & {$[14]$} \\
$M$ & 4.8 & fixed & {$[11]$} \\
$N$ & 5 & fixed & {$[14]$} \\
$m_{s}$ & 0.4 & fixed & {$[15]$} \\
\hline
\end{tabular}

Table 1: Parameters used for the computation of stress-strain curves and the evolution of the dislocation density and the order parameter. "Fixed" parameters were determined by independent experiments and "free" parameters were varied to fit the calculated to the experimental curves. 


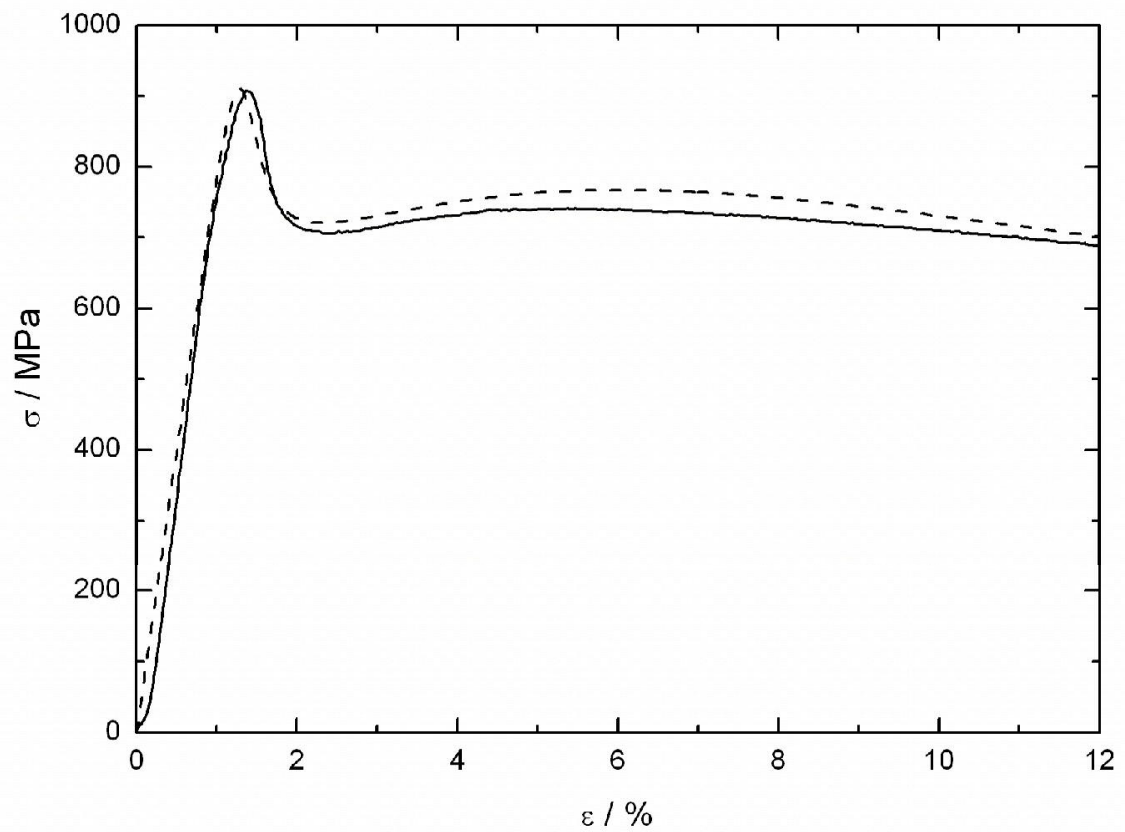

Figure 1: Experimental (solid line) and computed (broken line) stress-strain curves at 10$3 \mathrm{~s}-1$ and $730{ }^{\circ} \mathrm{C}$. Both curves show the appearance of a second stress maximum at around $5 \%$ strain. $705 \times 554 \mathrm{~mm}(72 \times 72$ DPI $)$ 

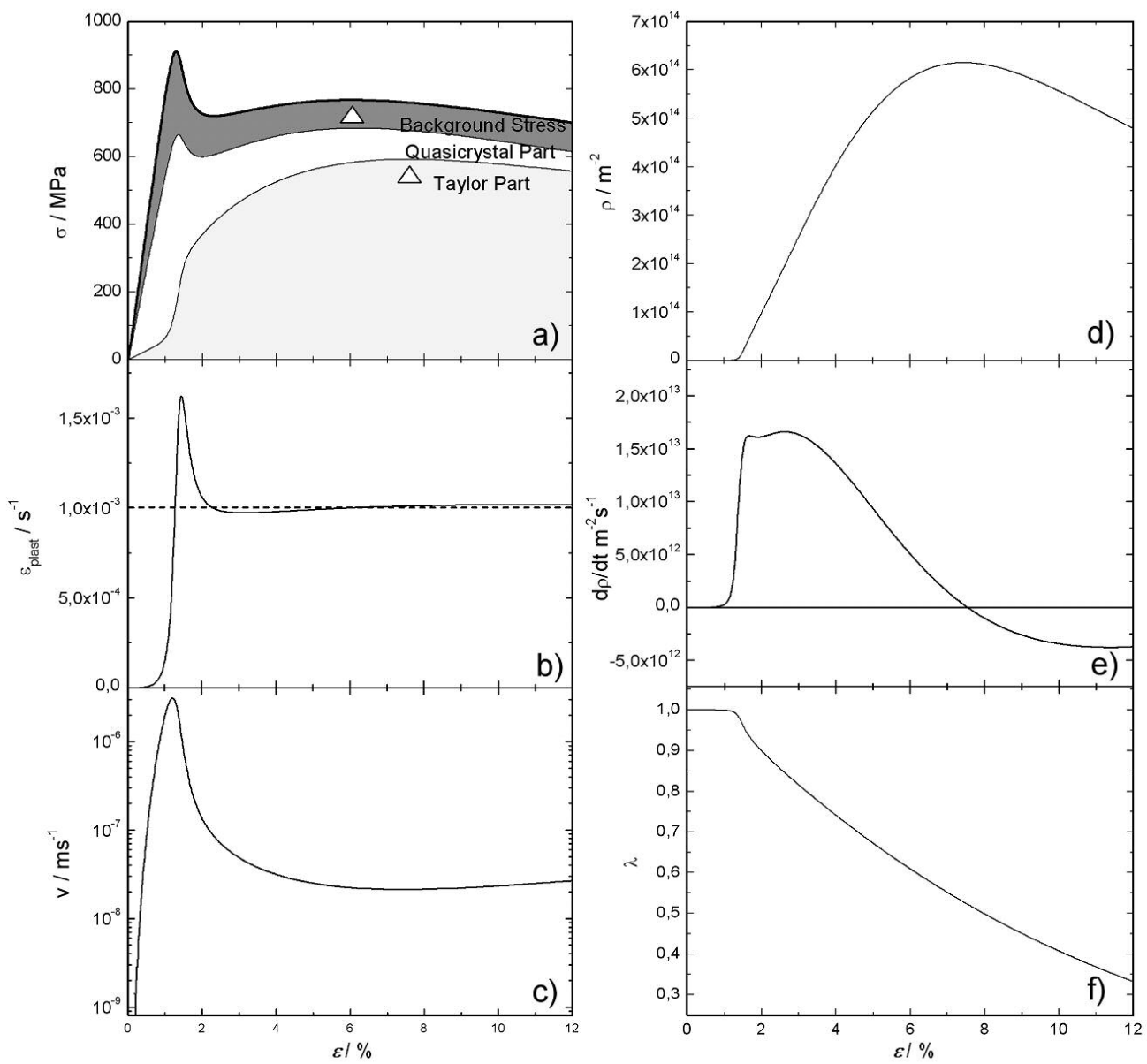

Figure 2: (a) Computed stress contributions, i.e. the Taylor part (light grey), the quasicrystal part (white) and the background stress (dark grey), at $730{ }^{\circ} \mathrm{C}$ and $\varepsilon \cdot=$ 10-3 s-1. The arrowheads indicate local maxima of the stress contributions. (b) Plastic strain rate, (c) dislocation velocity, (d) dislocation density, (e) rate of dislocation production and annihilation, and (f) order parameter. $464 \times 442 \mathrm{~mm}(72 \times 72 \mathrm{DPI})$ 